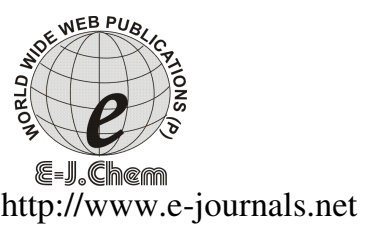

\title{
Simple Spectrophotometric Methods for the Determination of Zidovudine in Pharmaceuticals Using Chloramine-T, Methylene Blue and Rhodamine-B as Reagents
}

\author{
K BASAVAIAH* and U R ANIL KUMAR \\ Department of Chemistry, \\ University of Mysore, \\ Manasagangotri, Mysore 570 006, India
}

Received 7 May 2006; Accepted 2 June 2006.

\begin{abstract}
Two new spectrophotometric methods are proposed for the determination of zidovudine(ZDV) in pharmaceuticals. The methods use chloramine- $\mathrm{T}$ (CAT) and two dyes, methylene blue and rhodamine- $\mathrm{B}$, as reagents and are based on adding of a known excess of CAT to ZDV in hydrochloric acid medium followed by determination of residual oxidant by reacting with a fixed amount of either methylene blue and measuring the absorbance at $665 \mathrm{~nm}$ (Method A) or rhodamine B and measuring the absorbance at $555 \mathrm{~nm}$ (Method B). In both methods, the amount of CAT reacted corresponds to the amount of ZDV. The absorbance measured is found to increase linearly with concentration of ZDV. Under the optimum conditions, ZDV could be assayed in the concentration range 1.25-15.0 and 0.25-3.0 $\mu \mathrm{g} \mathrm{mL}^{-1}$ by method $\mathrm{A}$ and method $\mathrm{B}$, respectively. The apparent molar absorptivities are calculated to be $7.7 \times 10^{3}$ and $5.6 \times 10^{4} \mathrm{~L} \mathrm{~mol}^{-1} \mathrm{~cm}^{-1}$ for method A and method B, respectively, and the corresponding Sandell sensitivity values are 0.035 and $0.005 \mu \mathrm{g} \mathrm{cm}$. The limits of detection and quantification are reported for both methods. Intra-day and inter-day precision and accuracy of the developed methods were evaluated as per the current ICH guidelines. The proposed methods can be readily utilized for bulk drug and in pharmaceutical formulations.
\end{abstract}

Keywords: Zidovudine, assay, spectrophotometry, chloramine-T, formulations. 


\section{Introduction}

Zidovudine(ZDV) is chemically known as $3^{1}$-Azido- $3^{1}$-deoxy thymidine ${ }^{1}$ (Figure 1). It was the first drug approved for the treatment of AIDS and HIV infection. ZDV is a thymidine analogue ${ }^{1}$. It is phosphorylated in the body to zidovudine triphosphate, which is the active form that inhibits HIV replication ${ }^{2}$. ZDV inhibits the key enzyme reverse transcriptase.

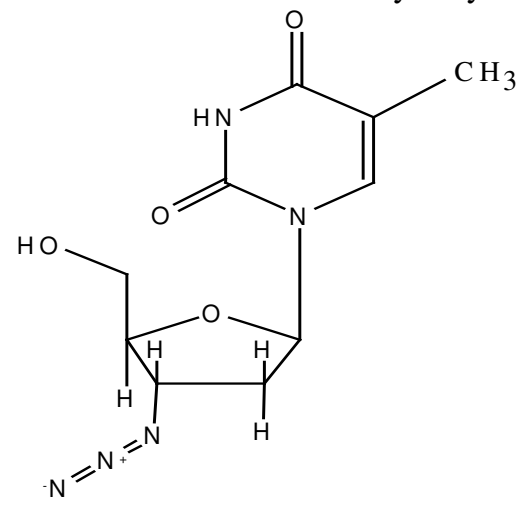

Figure 1. Structure of Zidovudine

High performance liquid chromatography (HPLC) is the single most widely used technique for the determination of $\mathrm{ZDV}$, but most of the studies are devoted to the determination of drug in body fluids such as human serum ${ }^{3-6}$, human plasma ${ }^{7-12}$, human plasma and urine ${ }^{13}$, and rat plasma ${ }^{14}$. There is only one report ${ }^{15}$ on the use of HPLC for the specific determination of ZDV in pure drug and marketed tablets. UV-spectrophotometry has also found application for the simultaneous determination of ZDV and lamivudine in human serum ${ }^{16}$. The technique in different modes has been applied for the assay of ZDV when present alone ${ }^{17}$ or in combination with lamivudine ${ }^{18}$ in pharmaceuticals.

Because of simplicity, reasonable accuracy and precision, and speed, visible spectrophotometry has withstood the test of time and remained competitive with the newer analytical methods including HPLC. However, literature survey revealed that no visible spectrophotometric method has ever been reported for the determination of ZDV in pharmaceuticals. The present investigation aims to develop sensitive and cost-effective methods for the determination of $\mathrm{ZDV}$ in pure form and in dosage forms using spectrophotometric technique. The methods utilize chloramine-T, which has successfully been used for the sensitive spectrophotometric determination of many bioactive substances $^{19-27}$, as an oxidimetric regent. The proposed methods have the advantages of speed and simplicity besides being accurate and precise, and can be adopted by the pharmaceutical laboratories for industrial quality control.

\section{Experimental}

\section{Reagents and Materials}

All chemicals used were of analytical reagent grade and distilled water was used to prepare all solutions. Chloramine-T solution $(0.005 \mathrm{M})$ was prepared by dissolving about $1.4 \mathrm{~g}$ of the chemical (Qualigens fine chem., Glaxo India Ltd., Mumbai) in water and diluting to 1 litre and standardised ${ }^{28}$. The solution was diluted appropriately with water to get 250 and $45 \mu \mathrm{g}$ $\mathrm{mL}^{-1}$ concentrations for method A and method B, respectively. To prepare $40 \mu \mathrm{g} \mathrm{mL}^{-1}$ 
methylene blue for method A, first, a $500 \mu \mathrm{g} \mathrm{mL} \mathrm{m}^{-1}$ dye solution was prepared by dissolving $71.5 \mathrm{mg}$ of dye (Qualigen fine-chem., Mumbai, assay 70\%) in water and diluting to $100 \mathrm{~mL}$ in a calibrated flask, and filtered using glass wool. This was appropriately diluted to get the required concentration. For method $\mathrm{B}$, first, a $500 \mu \mathrm{g} \mathrm{mL} \mathrm{L}^{-1}$ rhodamine B solution was prepared by dissolving $62.5 \mathrm{mg}$ of dye (s.d.fine-chem Ltd., Mumbai, $80 \%$ assay) in water and diluting to $100 \mathrm{~mL}$, and filterd. This was appropriately diluted with water to get $50 \mu \mathrm{g} \mathrm{mL}^{-1}$ dye solution. Hydrochloric acid (2M) was prepared by diluting $43 \mathrm{~mL}$ of concentrated acid (s.d.fine-chem Ltd., Mumbai, Sp gr 1.18) to $500 \mathrm{~mL}$ with water. Pharmaceutical grade ZDV, certified to be $99.8 \%$ pure was procured from Cipla India Ltd, Mumbai, India, and was used as received. A stock solution equivalent to $500 \mu \mathrm{g} \mathrm{mL}{ }^{-1} \mathrm{ZDV}$ was prepared by dissolving appropriate amount in water, and the solution was diluted with water to get working concentrations of 50 and $10 \mu \mathrm{g} \mathrm{mL}^{-1} \mathrm{ZDV}$ for method A and method B, respectively.

\section{Methods}

\section{Method Using Methylene Blue (Method A)}

Aliquots of pure ZDV solution $\left(0.5\right.$ to $\left.3.0 \mathrm{~mL} ; 50 \mu \mathrm{g} \mathrm{mL}^{-1}\right)$ were transferred into a series of $10 \mathrm{~mL}$ calibrated flasks by means of a micro burette and the total volume was adjusted to 3.0 $\mathrm{mL}$ with water. To each flask were added $2 \mathrm{~mL}$ of $2 \mathrm{M}$ hydrochloric acid followed by $1 \mathrm{~mL}$ of chloramine-T solution $\left(250 \mu \mathrm{g} \mathrm{mL}^{-1}\right)$. The content was mixed well and the flasks were set aside for $15 \mathrm{~min}$ with occasional shaking. Finally, $1 \mathrm{~mL}$ of $40 \mu \mathrm{g} \mathrm{mL} \mathrm{m}^{-1}$ methylene blue solution was added to each flask, diluted to the mark with water and the absorbance of solution was measured at $665 \mathrm{~nm}$ against reagent blank after $10 \mathrm{~min}$.

\section{Method Using Rhodamine B (Method B)}

Varying aliquots $(0.5-3.0 \mathrm{~mL})$ of standard $10 \mu \mathrm{g} \mathrm{mL} \mathrm{mL}^{-1} \mathrm{ZDV}$ solution were measured accurately and delivered into a series of $10 \mathrm{~mL}$ calibrated flasks and the total volume was brought to $3.0 \mathrm{~mL}$ with water. To each flask were added $2 \mathrm{~mL}$ each of $2 \mathrm{M}$ hydrochloric acid and $1 \mathrm{~mL}$ of $45 \mu \mathrm{g} \mathrm{mL}^{-1}$ chloramine-T solutions successively; the flasks were let stand for 15 min with occasional shaking. Then, $1 \mathrm{~mL}$ of $50 \mu \mathrm{g} \mathrm{mL}^{-1}$ rhodamine B solution was added to each flask, the volume was adjusted to the mark with water and mixed well. The absorbance of each solution was measured at $555 \mathrm{~nm}$ against a reagent blank after $10 \mathrm{~min}$.

In either spectrophotometric method, the concentration of the unknown was read from the calibration graph or computed from the regression equation derived from the Beer's law data.

\section{Assay Procedure for Formulations}

An amount of finely ground tablet/capsule powder equivalent to $100 \mathrm{mg}$ of ZDV was accurately weighed into a $100 \mathrm{~mL}$ calibrated flask, $60 \mathrm{~mL}$ of water added and shaken for 20 min. Then, the volume was made up to the mark with water, mixed well, and filtered using a Whatman No 42 filter paper. First $10 \mathrm{~mL}$ portion of the filtrate was discarded and a suitable aliquot of the subsequent portion $\left(1000 \mu \mathrm{g} \mathrm{mL}^{-1} \mathrm{ZDV}\right)$ was diluted appropriately to get 50 and $10 \mu \mathrm{g} \mathrm{mL}^{-1}$ concentrations for analysis by method $\mathrm{A}$ and method $\mathrm{B}$, respectively.

\section{Results and Discussion}

The proposed methods are based on the oxidation of ZDV by CAT in $\mathrm{HCl}$ medium and the reaction is followed spectrophotometry for quantization purposes. The methods are based on the determination of surplus chloramine-T after allowing the reaction between ZDV and 
oxidant to occur. The determination is accomplished by reacting with a fixed amount of either methylene blue or rhodamine B.

\section{Optimisation of Experimental Conditions}

ZDV when added in increasing concentrations to a fixed concentration of chloramine-T, consumes the latter and there will be a concomitant decrease in its concentration. When a fixed concentration of either dye is added to decreasing concentrations of chloramine- $\mathrm{T}$, a concomitant increase in the concentration of dye results and a proportional increase in the absorbance at the respective $\lambda_{\max }$ is observed with increasing concentration of ZDV.

Preliminary experiments were performed to fix the upper limits of the dyes that could be determined spectrophotometrically, and these were found to be 4 and $5 \mu \mathrm{g} \mathrm{mL}^{-1}$ for methylene blue and rhodamine $\mathrm{B}$, respectively. A chloramine-T concentration of $25 \mu \mathrm{g} \mathrm{mL}^{-1}$ was found to irreversibly destroy the blue colour of $4 \mu \mathrm{g} \mathrm{mL}^{-1}$ methylene blue whereas 4.5 $\mu \mathrm{g} \mathrm{mL} \mathrm{m}^{-1}$ chloramine- $\mathrm{T}$ was required to bleach red colour due to $5 \mu \mathrm{g} \mathrm{mL} \mathrm{m}^{-1}$ rhodamine $\mathrm{B}$. Hence, different amounts of ZDV were reacted with $1 \mathrm{~mL}$ of $250 \mu \mathrm{g} \mathrm{mL}^{-1}$ chloramine-T in method $\mathrm{A}$ and $1 \mathrm{~mL}$ of $45 \mu \mathrm{g} \mathrm{mL} \mathrm{m}^{-1}$ chloramine-T in method $\mathrm{B}$ followed by determination of the residual oxidant as described under the respective procedures.

For both oxidation of ZDV and bleaching of dyes by CAT, hydrochloric acid medium was found to be ideal. Two $\mathrm{mL}$ of $2 \mathrm{M}$ hydrochloric acid in a total volume of $\sim 3-4 \mathrm{~mL}$ was adequate for the oxidation step which was complete in $15 \mathrm{~min}$ in both methods and the same quantity of acid was employed for the estimation of the dye. Contact time of $15 \mathrm{~min}$ is not critical and any delay upto $30 \mathrm{~min}$ had no effect on the absorbance.

\section{Analytical Data}

A linear correlation was found between absorbance at $\lambda_{\max }$ and concentration of ZDV. The graphs showed negligible intercept and are described by the equation: $Y=a+b X$

(where $\mathrm{Y}=$ absorbance of $1-\mathrm{cm}$ layer of solution; $\mathrm{a}=$ intercept; $\mathrm{b}=$ slope and $\mathrm{X}=$ concentration in $\mu \mathrm{g} \mathrm{mL}^{-1}$ ) . Regression analysis of the Beer's law data using the method of least squares was made to evaluate the slope(b), intercept(a) and correlation coefficient( $r$ ) for each system and the values are presented in Table 1. The optical characteristics such as Beer's law limits, molar absorptivity and Sandell sensitivity values of both methods are also given in Table 1. The limits of detection (LOD) and quantitation(LOQ) calculated according to $\mathrm{ICH}$ guidelines ${ }^{29}$ are also presented in Table. 1 and reveal the very high sensitivity of the spectrophotometric methods.

\section{Method Validation \\ Accuracy and Precision}

To evaluate the accuracy and precision of the methods, pure drug solution at three different levels (within the working limits) was analysed, each determination being repeated seven times. The relative error (\%) and relative standard deviation (\%) were less than 2.0 and indicate the high accuracy and precision for the methods (Table 2). For a better picture of reproducibility on a day-to-day basis, a series of experiments were performed in which standard drug solution at three different levels was determined each day for five days with all solutions being prepared afresh each day. The day-to-day relative standard deviation values were in the range of $2.2-2.7 \%$ and represent the best appraisal of the methods in routine use. 
Table 1. Analytical and Regression Parameters of Spectrophotometric Methods

\begin{tabular}{lcc}
\hline \multicolumn{1}{c}{ Parameter } & Method A & Method B \\
\hline$\lambda_{\max }, \mathrm{nm}$ & 665 & 555 \\
Beer's law limits, $\mu \mathrm{g} \mathrm{mL}^{-1}$ & $1.25-15.0$ & $0.25-3.0$ \\
Molar absorptivity, $\mathrm{mol}^{-1} \mathrm{~cm}^{-1}$ & $7.7 \times 10^{3}$ & $5.6 \times 10^{4}$ \\
Sandell sensitivity, $\mu \mathrm{g} \mathrm{cm}^{-2}$ & 0.0346 & 0.0047 \\
Limit of detection, $\mu \mathrm{g} \mathrm{mL}^{-1}$ & 0.24 & 0.03 \\
Limit of quantification, $\mu \mathrm{g} \mathrm{mL}^{-1}$ & 0.73 & 0.08 \\
Regression equation, $\mathrm{Y}^{*}$ & & \\
Intercept (a) & -0.006 & -0.004 \\
Slope (b) & 0.030 & 0.217 \\
Correlation coefficient, (r) & 0.9998 & 0.9996 \\
$\mathrm{~S}_{\mathrm{a}}$ & 0.003 & 0.006 \\
$\mathrm{~S}_{\mathrm{b}}$ & 0.0003 & 0.003 \\
\end{tabular}

$* \mathrm{Y}=\mathrm{a}+\mathrm{bX}$, where $\mathrm{Y}$ is the absorbance and $\mathrm{X}$ concentration in $\mu \mathrm{g} \mathrm{mL}$

$\mathrm{S}_{\mathrm{a}}=$ Standard deviation of intercept.

$\mathrm{S}_{\mathrm{b}}=$ Standard deviation of slope.

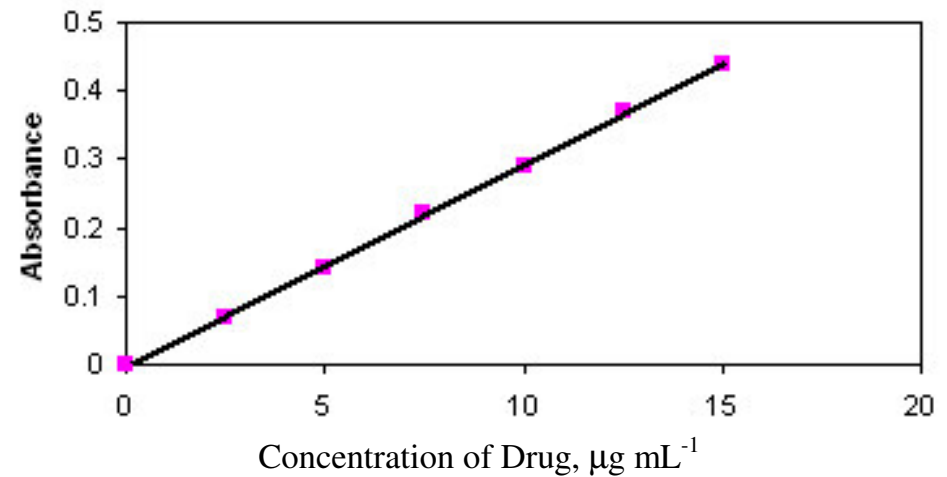

Figure 2. Beer's Law Curve for Method A

\section{Application to Analysis of Commercial Samples}

In order to check the validity of the proposed methods, ZDV was determined in some commercial formulations. Table 3 gives the results of the determination from which it is clear that there is close agreement between the results obtained by the proposed methods and the label claim. The results were also compared statistically by a Student's t- test for accuracy and variance ratio F- test for precision with those of the reference method ${ }^{17}$ at $95 \%$ confidence level. The calculated t- and F-values (Table 3) did not exceed the tabulated values ( $t=2.77, \mathrm{~F}=6.39$ ) except in a couple of instances for four degrees of freedom indicating that there was no significant difference between the proposed methods and the reference method in respect to accuracy and precision. 


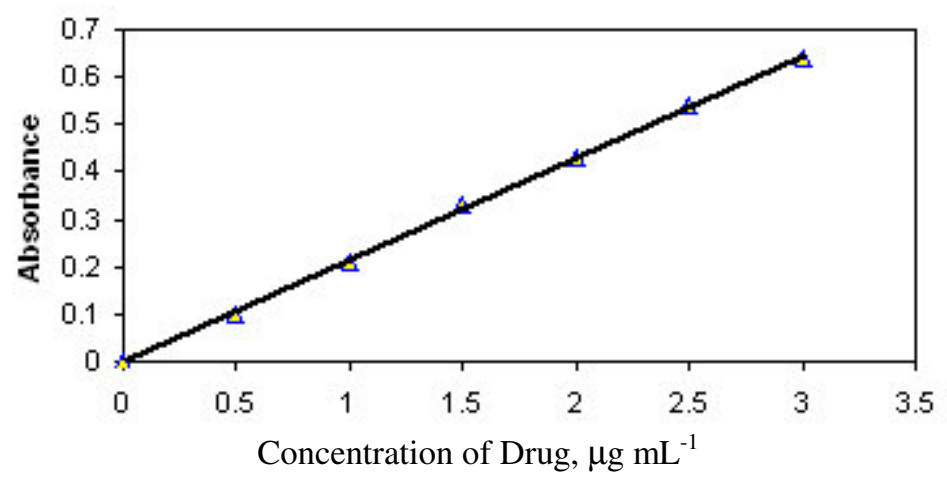

Figure 3. Beer's Law Curve for Method B

Table 2- Evaluation of Accuracy and Precision

\begin{tabular}{ccccccccc}
\hline Method* & $\begin{array}{c}\text { ZDV } \\
\text { taken }\end{array}$ & $\begin{array}{c}\text { ZDV } \\
\text { Found** }\end{array}$ & Range & $\begin{array}{c}\text { RE } \\
\%\end{array}$ & SD & $\begin{array}{c}\text { SEM } \\
\text { RSD } \\
\%\end{array}$ & $\begin{array}{c}\text { ROE,*** } \\
\%\end{array}$ \\
\hline \multirow{3}{*}{ Method A } & 5.0 & 4.95 & 0.14 & 0.91 & 0.05 & 0.02 & 1.02 & \pm 1.02 \\
& 10.0 & 9.89 & 0.26 & 1.15 & 0.10 & 0.04 & 0.96 & \pm 0.96 \\
& 15.0 & 14.84 & 0.40 & 1.07 & 0.13 & 0.05 & 0.90 & \pm 0.90 \\
Method B & 1.0 & 0.98 & 0.05 & 1.88 & 0.02 & 0.01 & 1.65 & \pm 1.65 \\
& 2.0 & 1.96 & 0.10 & 1.87 & 0.03 & 0.01 & 1.75 & \pm 1.75 \\
& 3.0 & 3.05 & 0.10 & 1.65 & 0.04 & 0.02 & 1.35 & \pm 1.35 \\
\hline
\end{tabular}

RE relative error; SD. Standard deviation; SEM .Standard error of mean; RSD. Relative standard deviation; ROE.Range of error; * Mean value of seven determinations; ** At the 95\% confidence level for 6 degrees of freedom.

Table 3. Results of Determination of Zidovudine in Formulations and Statistical Comparison with the Reference Method

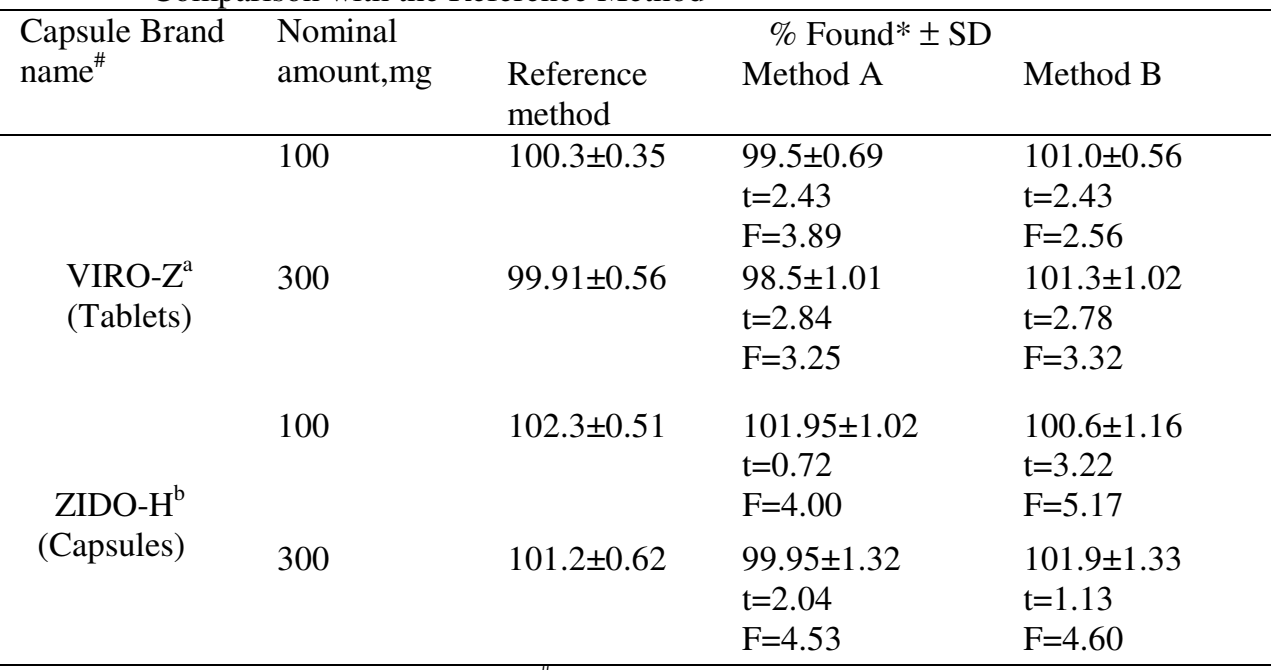

*Mean value of five determinations; ${ }^{\#}$ Marketed by: a. Ranbaxy Ltd. India.; b. Genix Ltd.

Tabulated t-value at $95 \%$ confidence level is 2.77

Tabulated F-value at 95\% confidence level is 6.39. 
Table 4. Results of Recovery Experiments by Standard Addition Method

\begin{tabular}{|c|c|c|c|c|c|c|c|c|}
\hline \multirow[t]{2}{*}{$\begin{array}{l}\text { Formulation } \\
\text { studied }\end{array}$} & \multicolumn{4}{|c|}{ Spectrophotometric Method A } & \multicolumn{4}{|c|}{ Spectrophotometric Method B } \\
\hline & $\begin{array}{l}\text { Amount of } \\
\text { drug in } \\
\text { tablet, } \mu \mathrm{g}\end{array}$ & $\begin{array}{l}\text { Amount of } \\
\text { pure drug } \\
\text { added, } \mu \mathrm{g}\end{array}$ & $\begin{array}{l}\text { Total } \\
\text { found, } \\
\mu \mathrm{g}\end{array}$ & $\begin{array}{l}\text { Pure drug } \\
\text { recovered*, } \\
\%\end{array}$ & $\begin{array}{l}\text { Amount of } \\
\text { drug in } \\
\text { tablet, } \mu \mathrm{g}\end{array}$ & $\begin{array}{l}\text { Amount of } \\
\text { pure drug } \\
\text { added, } \mu \mathrm{g}\end{array}$ & $\begin{array}{l}\text { Total } \\
\text { found, } \\
\mu \mathrm{g}\end{array}$ & $\begin{array}{l}\text { Pure drug } \\
\text { recovered* } \\
\%\end{array}$ \\
\hline \multirow{3}{*}{ VIRO-Z 100} & 49.75 & 25 & 75.55 & 103.2 & 10.10 & 5 & 15.16 & 101.2 \\
\hline & 49.75 & 50 & 99.55 & 99.6 & 10.10 & 10 & 20.35 & 102.5 \\
\hline & 49.75 & 100 & 150.05 & 100.3 & 10.10 & 15 & 25.24 & 100.9 \\
\hline \multirow{3}{*}{ ZIDO-H 300} & 49.98 & 25 & 75.51 & 102.1 & 10.20 & 5 & 15.19 & 99.8 \\
\hline & 49.98 & 50 & 99.08 & 98.2 & 10.20 & 10 & 20.03 & 98.3 \\
\hline & 49.98 & 100 & 150.30 & 100.5 & 10.20 & 15 & 25.28 & 100.5 \\
\hline
\end{tabular}

*Mean value of three determinations 
The accuracy and validity of the proposed methods were further ascertained by performing recovery studies. Pre-analysed tablet or capsule powder was spiked with pure ZDV at three different levels and the total was found by the proposed methods. Each determination was repeated three times. The recovery of the pure drug added was quantitative and revealed that co-formulated substances such as talc, starch, gum acacia, sucrose, sodium alginate, magnesium stearate, calcium carbonate, calcium gluconate and calcium dihydrogenorthophosphate did not interfere in the determination. The results of recovery study are compiled in Table-4.

\section{Conclusions}

Two useful micro methods for the determination of ZDV have been developed and validated. The methods are simple and rapid taking not more than 20-25 min for the assay. Both spectrophotometric methods are more sensitive than the existing UV and HPLC methods, and are free from such experimental variables as heating or exctraction step. The methods rely on the use of simple and cheap chemicals and techniques but provide sensitivity comparable to that achieved by sophisticated and expensive technique like HPLC. Thus, they can be used as alternatives for rapid and routine determination of bulk sample and tablets.

\section{References}

1. Yarchoan R, Mitsuya S and Broder, AIDS therapies, Sci Am. 1988, 259, 110.

2. Mitsuya H, Yarchoan R and Broder S, Molecular targets for AIDS Therapy Science. 1990, 249, 1533.

3. Uslu Bengi and Ozkan Sibel A Anal. Chim. Acta. 2002, 466, 175.

4. Nebinger peter, Koel and Marlies J.Pharm.and Biomed Anal. 1994, 12, 141.

5. Simon V A and Thiam M D, J.Chromatogr.A. 2001, 913, 447.

6. Kenney K B, wring S A, Carr R M, Wells G N and Dunn J A, J.Pharm.Biomed. Anal. 2000, 22, 967.

7. Rezk Naser L, Tidwell Richard R and Kashuba Angela D M, J.Chromatogr.B,Anal. Technol. Biomed. Life Sci. 2003, 791, 137.

8. Marchei Emilia, Valvo Luisa, Pacifici Roberta, Pellegrini Manuela, Tossini Gianna and Zuccaro piergiorgio, J.Pharm.Biomed. Anal. 2002, 29, 1081.

9. Fan Bin and Stewart James T J.Pharm.Biomed. Anal. 2002, 28, 903.

10. Aymard G, Legrand M, Trichereau N and Diquet B, J.Chromatogr.B,Biomed. Sci. Appl. 2000, 744, 227.

11. Burger D M, Rosing H, Koopman F J, Mennhorst P L, Mulder J W, Bult A and Beijnen J H, J.Chromatogr. 1993, 622, 235.

12. Mazzei M, Balbi A, Sottofattori E, Bruzzo C,Palamone G and Nicolin A, Farmaco. 1990,45,737.

13. Underberg W J M, Underberg-Chitoe U K, Bekers O, Meenhorst P L and Beijnen J H, Int. J. Pharm. 1989, 50, 175.

14. Kong Linghui, John S, Oh Chang $\mathrm{H}$, Chu Chang $\mathrm{K}$ and Boudinot $\mathrm{F}$, J.Chromatogr.B,Anal. Technol. Biomed. Life Sci. 2003, 795, 371.

15. Ashenafi Dunge, Nishi Sharda, Baljinder singh and Saranjit singh, J.Pharm. Biomed. Anal. 2005, 37, 1109.

16. Erk N Die, Pharmazie, 2004, 59,106. 
17. Randau,Karina Perelli, Meira, Juliana Lima, Braga, Jovita Maria de Farias, Monterio,Deborah Bezerra, Rolim Neto and Pedro Jose, Acta Farmaceutica Bonaerense. 2005, 24, 104.

18. Erk N Pharmazie. 2004, 59, 106.

19. Basavaiah K, Manjunatha swamy J and Krishnamurthy G, Anal Lett. 1999,32, 2613.

20. Basavaiah K and Manjunatha swamy J, Anal.Sci. 2001, 17, 964.

21. Basavaiah K and Manjunatha swamy J, Turkish J Chem. 2002, 26, 551.

22. Basavaiah K and Nagegowda P, Bulg.Chem Commun. 2003, 35, 48.

23. Basavaiah K and Prameela H C, Bulg.Chem Commun. 2003, 35, 37.

24. Basavaiah K and Prameela H C, IL Farmaco. 2003,58, 527.

25. Basavaiah K and Prameela H C, Anal.Sci. 2003,19, 779.

26. Basavaiah K and Chandrashekar U, Indian J.Chem.Technol. 2004, 11, 769.

27. Basavaiah K and Nagegowda P, Oxid commun. 2004, 27, 203.

28. Berka A,Vulterin $\mathrm{J}$ and Zyka J, Newer Redox Titrants (Pergamon press, London), 1965,38 .

29. Validation of Analytical Procedures; Methodology, International Conference on Hormonization Harmonization (ICH), 1994,6. 


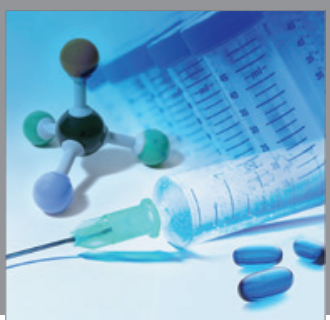

International Journal of

Medicinal Chemistry

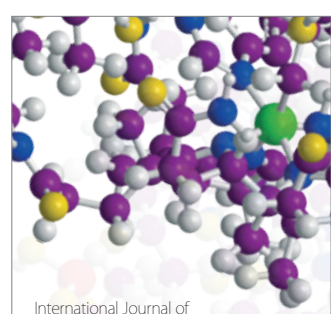

Carbohydrate Chemistry

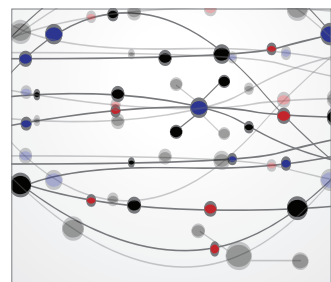

The Scientific World Journal
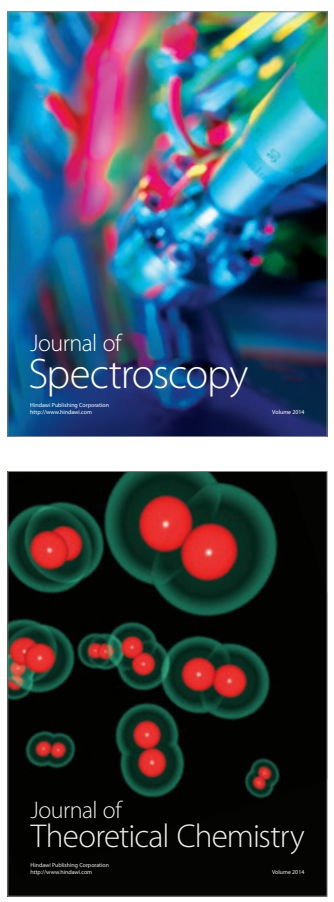
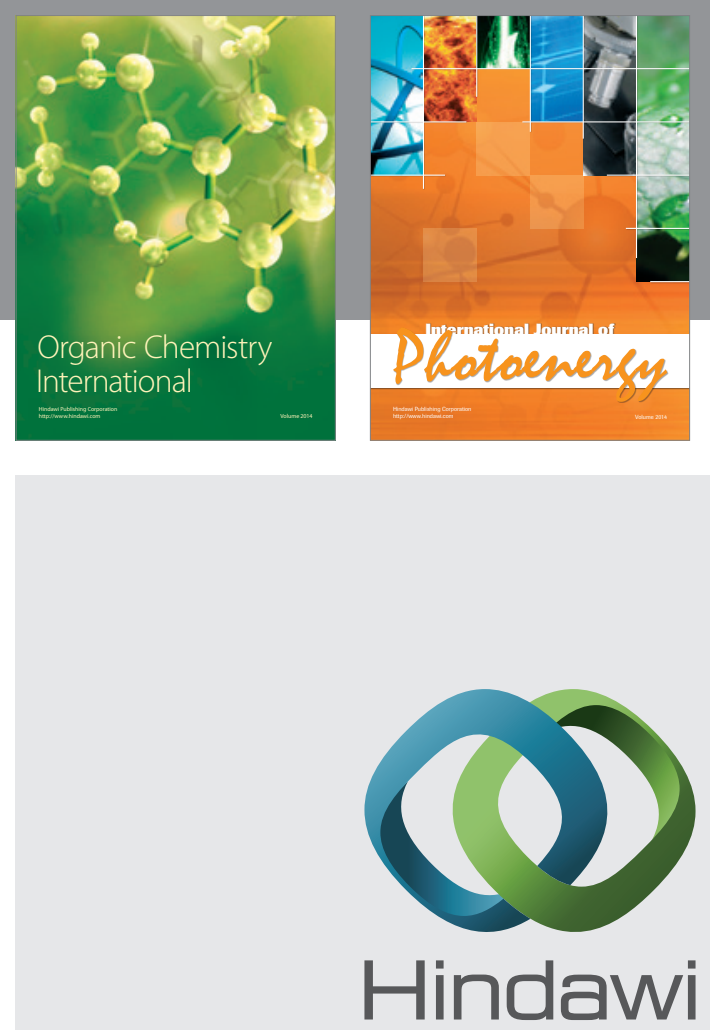

Submit your manuscripts at

http://www.hindawi.com
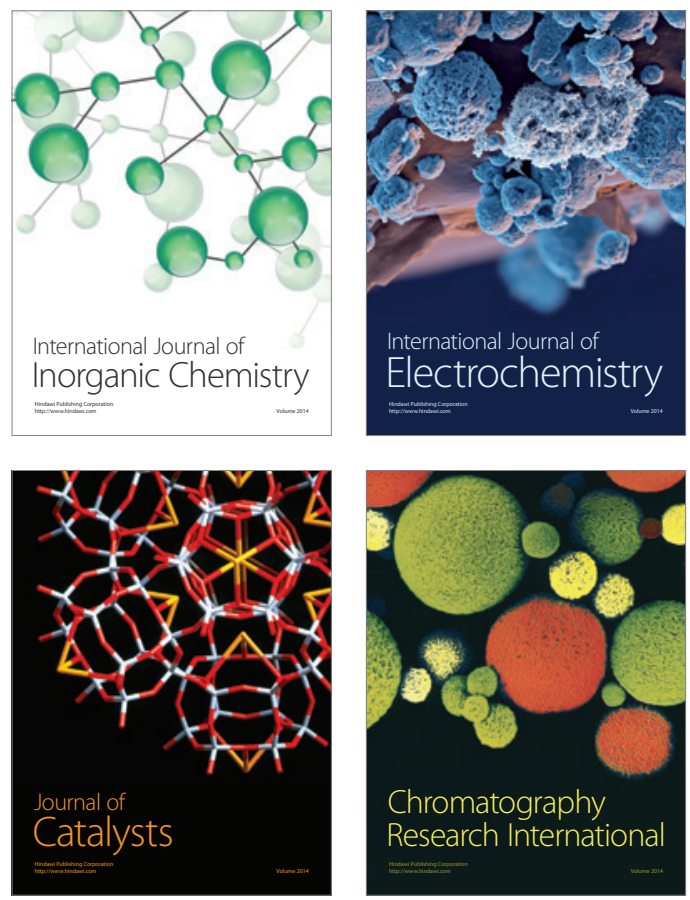
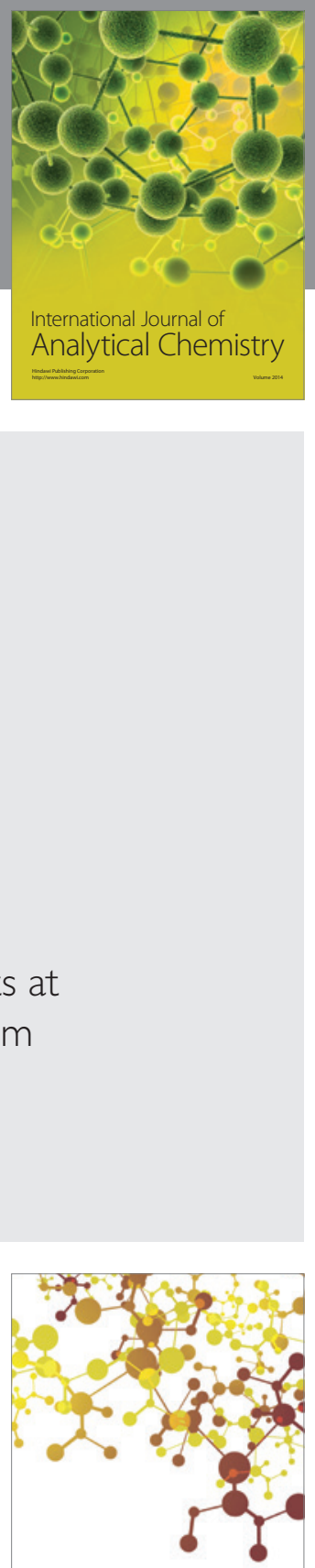

Journal of

Applied Chemistry
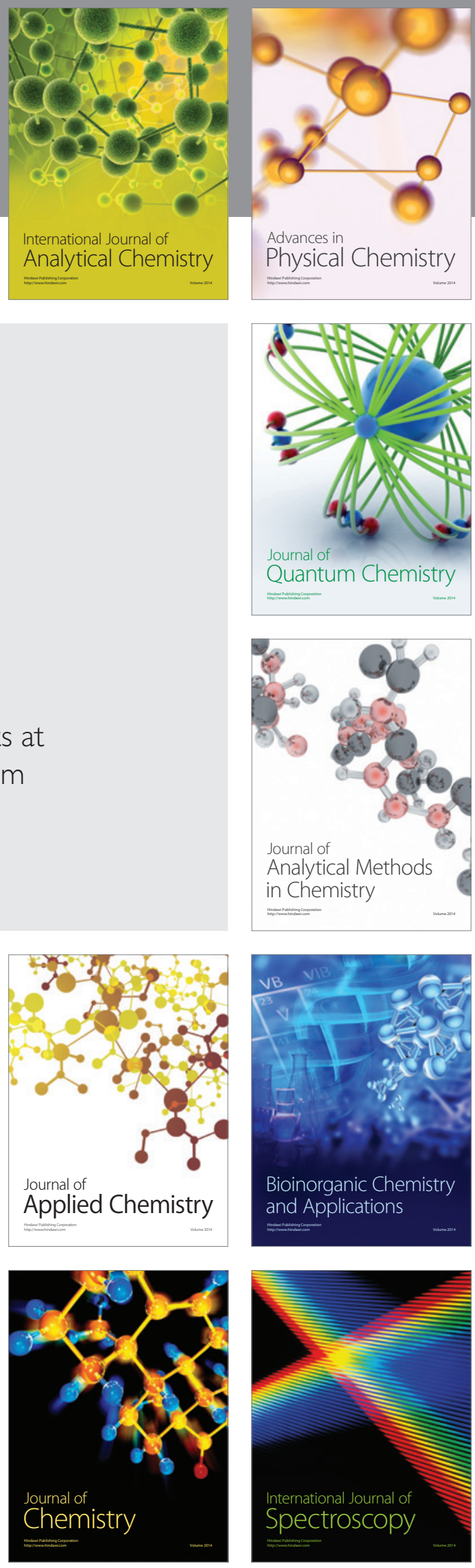